\title{
Effect of Different Levels of Wine Yeast and Sugar in Wine Production from Pineapple (Ananas comosus)
}

\author{
Kithan Thungbeni*, Topno E. Samir and Wilson Deena \\ Department of Horticulture, Sam Higginbottom University of Agriculture, Technology and \\ Sciences, Prayagraj, India \\ *Corresponding author
}

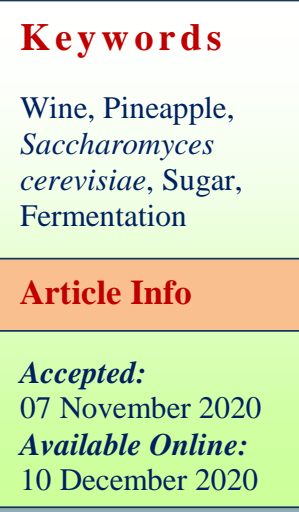

A B S T R A C T

\begin{abstract}
The study was conducted in Completely Randomized Design (CRD) with 9 treatments replicated thrice. The treatments were $\mathrm{T}_{1}$ (Pineapple juice $700 \mathrm{ml}+$ Sugar $150 \mathrm{~g}+$ Wine Yeast $0.25 \mathrm{~g}$ ), $\mathrm{T}_{2}$ (Pineapple juice $700 \mathrm{ml}+$ Sugar $200 \mathrm{~g}+$ Wine Yeast $1.5 \mathrm{~g}$ ), $\mathrm{T}_{3}$ (Pineapple juice $700 \mathrm{ml}+$ Sugar $250 \mathrm{~g}+$ Wine Yeast $0.75 \mathrm{~g}$ ), $\mathrm{T}_{4}$ (Pineapple juice $700 \mathrm{ml}+$ Sugar $150 \mathrm{~g}$ + Wine Yeast $0.75 \mathrm{~g}$ ), $\mathrm{T}_{5}$ (Pineapple juice $700 \mathrm{ml}+$ Sugar $200 \mathrm{~g}+$ Wine Yeast $0.25 \mathrm{~g}$ ), $\mathrm{T}_{6}$ (Pineapple juice $700 \mathrm{ml}+$ Sugar $250 \mathrm{~g}+$ Wine Yeast $1.5 \mathrm{~g}$ ), $\mathrm{T}_{7}$ (Pineapple juice $700 \mathrm{ml}+$ Sugar $150 \mathrm{~g}+$ Wine Yeast $1.5 \mathrm{~g}$ ), $\mathrm{T}_{8}$ (Pineapple juice $700 \mathrm{ml}+$ Sugar $200 \mathrm{~g}+$ Wine Yeast $0.75 \mathrm{~g}$ ) and $\mathrm{T}_{9}$ (Pineapple juice $700 \mathrm{ml}+$ Sugar $250 \mathrm{~g}+$ Wine Yeast $0.25 \mathrm{~g}$ ). Total soluble solids, pH and Specific Gravity decreased while the alcohol content, Acidity and the Sensory Qualities increased with increasing length of fermentation. From the above treatments, it is concluded that treatment $\mathrm{T}_{2}$ was found superior in respect of the parameters like Total Soluble Solids, Acidity, pH, Alcohol content, Specific gravity. With respectively Colour and Appearance, Taste, Aroma and Overall acceptability also $\mathrm{T}_{2}$ was found best. In terms of cost benefit ratio, the highest net return, Cost Benefit Ratio was found in $\mathrm{T}_{4}$. Since Pineapples contains good sugar proportion which makes it suitable for wine making, the production of wine from this fruit can help increase wine variety and reduce post-harvest losses. This study showed that acceptable wine can be produced from pineapple using yeast especially Saccharomyces cerevisiae.
\end{abstract}

\section{Introduction}

In recent years, increasing interest in human health, nutrition and disease prevention has enlarged consumer's demand for functional foods including fruits and their products such as wine. Functional or health-enhanced foods include "those in which the concentrations of one or more ingredients have been manipulated or modified to enhance their contribution to a healthy diet" (American Dietetic Association, 2004). The functional interest in wine, particularly red wine can be traced to the term "French paradox" referring to the observation that French people consume a high saturated fat diet, but their mortality rate from coronary heart disease is low because of high wine consumption. Longterm moderate consumption of wine has reportedly reduced the incidence of ailments 
such as risk of coronary heart disease (Leikert et al., 2002), atherosclerosis (Vinson et al., 2001) and cancers, attributed to phytoalexins like resveratrol present in wine which have cancer chemo-preventive activity (Michael et al., 1993; Meshing et al., 1997). Recent study suggests that, wine consumption is correlated with reduction of neurodegenerative disorders associated to oxidative stress such as Alzheimer's and Parkinson's diseases (Sun et $a l ., 2008)$. With these evident potential health benefits of wine, interest in fruit wines have been accordingly aroused and nowadays consumers are perceiving wine as a healthy product (Yang et al., 2009; Das et al., 2010).

Wine making is an ancient practice in many countries and considerable work has been done on various aspects of wine making from different fruits. The character and quality depend mainly on the variety and composition of the fruits. Fruit wines are non-distilled alcoholic beverages that are more tasty, nutritious and delicate stimulants. Wines are often named after the fruits from which they are made. Consumers from geographically and socially different areas have specific preferences and expectations of wine products. Asian and western cultures like different types of fruit wines because of their diverse food preferences (Lee et al., 2005). The basic process of wine making involves the fermentation of fruit juice by Saccharomyces cerevisiae to ethanol followed by maturation to prepare wine (Joshi et al., 2009). Yeasts are the most important and extensively used microbes in the wine industry and among the alcoholic fermentation yeast Saccharomyces cerevisiae appears to be the most commonly used (Kirtadze and Nutsubidze, 2009). The process depends on the performance of yeast to convert sugar to alcohol and properties of wine strictly depend upon the specific yeast strains (Fleet, 2003; Duarte et al., 2009; Duarte et al., 2010). The selection of suitable yeast is thus important to ensure a complete fermentation and to improve the final characteristics of fermented beverage, as yeasts can produce compounds that provide a distinctive flavour and aroma to the final product. Selection of suitable yeast can provide a distinctive touch to the final product (Alves et al., 2011). Usually, fruits with characteristic pleasant flavour and aroma are preferred for wine making. Pineapple is one such fruit popularly liked because of its flavour, and thus suitable for wine making.

The production of wine from pineapple serves as a way to prolong its shelf life and add economic value (Clemente and Scapim, 2005). Pineapple (Ananas comosus) belongs to the family Bromeliaceae and originated in South America (Barthelomew et al., 2003). In recent years, pineapple wine as value-added product has become more popular because of its appealing flavour, it is one of the nonvintage wines which is produced and fermented in a manner similar to grape wines. The juice contains a unique fruity flavour and has sufficient nutrients, including nitrogen for yeast growth and fermentation, giving acceptable wine characters (Callens and De Smet, 1991; Ruengrongpanya, 1996; Ayogu, 1999). Major steps during production of pineapple wine include peeling and cutting of fruit, juice extraction, fermentation, clarification, bottling and maturation (Youravong et al., 2010).

Preparation of wine from fruits other than grapes has increased in recent years, such as kiwi (Souflerosa et al., 2001), banana (Akubor et al., 2003), caja (Dias et al., 2003), mango (Kumar et al., 2009), gabiroba (Duarte et al., 2009), cocoa and cupuassu (Duarte et al., 2010), wherein apples and oranges have been widely used. Wine ageing and its ability to potentially improve wine quality for its consumption is most important step after wine production. Storage is an important 
consideration for wine that is being kept for long-term ageing and, fresh wine should be aged till it is drinkable and marketable, thus the evolution of the product in the bottle before its consumption is very important. It is usually aged for an extensive period for the maturation of flavours, and wine is one of the few commodities that can improve with age but it can also rapidly deteriorate if kept in un- favourable conditions.

The composition of wine is subjected to continuous changes during storage and these changes are a result of a function of parameters such as temperature, illumination, position of bottles, oxygen content and storage time (Dallas and Laureano, 1994). These changes are varied and intricate and can affect its aroma and colour.

These fruits are highly perishable and exhibit very short shelf life. Growers face the problem of marketing, as the ripe fruits cannot be easily transported over long distances and to niche markets, because of high moisture and active metabolism which accelerates the deterioration of the fruit soon after harvest (Netto et al., 2005). Thus, postharvest loss of pineapple fruit remains a substantial problem (15-20\% of the total production). Hence, there is a need to develop postharvest technologies and processing protocols, aimed at value-added products and valorisation.

\section{Materials and Methods}

The study was conducted in Completely Randomized Design (CRD) with 9 treatments replicated thrice. The treatments were $T_{1}$ (Pineapple juice 700ml + Sugar 150g + Wine Yeast $0.25 \mathrm{~g}$ ), $\mathrm{T}_{2}$ (Pineapple juice $700 \mathrm{ml}+$ Wine Sugar 200g + Yeast 1.5g), $\mathrm{T}_{3}$ (Pineapple juice 700ml + Sugar 250g + Wine Yeast $0.75 \mathrm{~g}$ ), $\mathrm{T}_{4}$ (Pineapple juice $700 \mathrm{ml}+$ Sugar $150 \mathrm{~g}+$ Wine Yeast $0.75 \mathrm{~g}), \mathrm{T}_{5}$
(Pineapple juice 700ml + Sugar 200g + Wine Yeast $0.25 \mathrm{~g}$ ), $\mathrm{T}_{6}$ (Pineapple juice $700 \mathrm{ml}+$ Sugar $250 \mathrm{~g}+$ Wine Yeast $1.5 \mathrm{~g}), \mathrm{T}_{7}$ (Pineapple juice 700ml + Sugar 150g + Wine Yeast $1.5 \mathrm{~g}$ ), $\mathrm{T}_{8}$ (Pineapple juice $700 \mathrm{ml}+$ Sugar $200 \mathrm{~g}+$ Wine Yeast $0.75 \mathrm{~g}$ ) and $\mathrm{T}_{9}$ (Pineapple juice 700ml + Sugar 250g + Wine Yeast $0.25 \mathrm{~g}$ ).

\section{Sorting of fruits}

The fruits were examined for rotting. Completely rotten fruits were discarded and rotten part of other fruits was removed.

\section{Washing of fruits}

The fruits to be processed were washed thoroughly under tap water to remove dust, dirt and other undesired materials adhering to the fruits.

\section{Cutting of fruit}

All the selected fruits were cut into thin slices of about $1 \mathrm{~cm}$ thickness. A stainless-steel knife was used for the same.

\section{Source of raw material}

The ripen pineapple fruits were procured locally and stored for 12 hours in the Postharvest Laboratory at the Department of Horticulture, Sam Higginbottom University of Agriculture, Technology and sciences, Prayagraj at room temperature. At its optimum and wholesome stage for wine production the fruits were washed, weighed and must (Will et al.; 1998) prepared from it. On $7^{\text {th }}$ September 2019 processing was started. Commercial wine yeast Saccharomyces cerevisiae Lalvin (EC-1118) used in fermentation was obtained from Vinsura Winery Pvt. Ltd, Lasalgaon Nashik, Mumbai. 


\section{Preparation of must}

Mature pineapple fruits were selected and washed with tap water, removed the crown, skin peeled, sliced and cut into pieces and pulverized using sterile Philip electric blender with the addition of water. The slurry was further diluted in a ratio of 1:1 (water and pulp) and sieved with a muslin cloth of pore size $0.8 \mathrm{~mm}$ to obtain the filtrate must". Chaptalization and supplementation of the "Must". The methods of Amerine and Kunkee as used by Robinson were used. These bottled juices were cold stored till further experiments were conducted.

\section{Preparation of bottles}

Bottles were washed thoroughly with hot water and kept it for sun dry and get it sterilized.

\section{Preparation of yeast starter culture}

The yeast starter culture was prepared from a known quantity of the must for fermentation, small quantity of sugar, yeast and a known volume of water. The mixture of all these were treated and allowed to stand for $24 \mathrm{~h}$. Approximately $200 \mathrm{ml}$ of water was boiled and allowed to attain $37{ }^{\circ} \mathrm{C}$ and $200 \mathrm{ml}$ of the mixture of pineapple must respectively treated with sugar was added.

Exactly $3.7 \mathrm{ml}$ representing approximately $108 \mathrm{cfu} / \mathrm{ml}$ (measured using McFarland standard) of the yeast (S. cerevisiae) after centrifugation was added to the mixture, stirred properly and allowed to stand for $24 \mathrm{~h}$ before use.

\section{Fermentation of must}

The primary fermentation was initiated by the addition of the starter culture. The must was stirred every $12 \mathrm{~h}$ with subsequent reading of the specific gravity, $\mathrm{pH}$, temperature and alcohol content for 4 days. After 4 days, the wine was racked into the secondary fermenter. The secondary fermentation was done in an air tight container in which a tube was passed into a clean bottle containing clean water. The essence was to monitor the course of fermentation. This was allowed until completion of fermentation as was evidenced by lack of the appearance of bubbles in the container usually within 3 weeks. Secondary fermentation was done for 21 days. When fermentation stopped, the wine was promptly racked off the lees ensuring mini-mum exposure to oxygen, the upper liquid was transfer to the other clean container in order to remove impurities.

Then the mixture continued to ferment at $20^{\circ} \mathrm{C}$ for more days. After that, under the storage conditions of $20^{\circ} \mathrm{C}$ aged 3 months. Microbial analysis, alcohol, sugar content, specific gravity, titratable acidity and $\mathrm{pH}$ of the wine were also monitored at the end of the secondary fermentation.

\section{Clarification of wine}

After completion of fermentation, the obtained wine was siphoned off and filtered through a clean sterilized muslin cloth, Whatman No.1 filter paper, sieve and syphon tubes sterilized by $70 \%$ alcohol and collected in sterile glass jars. The wine was racked for a period of 3 weeks to clear the wine. The residues were removed and the filtrates were allowed to mature before other chemical analysis was carried out. Clarification is an important procedure in wine production as the fermented wine contains sediments.

\section{Maturation of wine}

After clarification, the wine was kept in the refrigerator for maturation (2 weeks) and then packaged for further analysis. 


\section{Aging}

Wine ageing and its ability to potentially improve wine quality for its consumption is most important step after wine production. After maturation, the supernatant was taken off and transferred into fresh sterile bottles, corked and subjected for pasteurization at $82^{\circ} \mathrm{C}$ for 20 minutes. After cooling, further allowed to age in long neck $750 \mathrm{ml}$ bottles for 17 days at $22-25^{\circ} \mathrm{C}$ before analysis (Chowdhury and Ray, 2007). The wine was analysed for physio- chemical properties at 30 days interval after 30 days from fermentation i.e., 30, 60, 90 days. Wines were also evaluated organoleptically after maturation with panel of judges for knowing the acceptance by different categories of consumers.

\section{Packaging and preservation}

The mature wine should be packed in clean containers for storage and marketing. The classical packaging material for wine is glass, appreciated primarily for its inertness and clarity. The bottles in which the wine will be packed should be sterilized to ensure the microorganisms load is reduced substantially.

\section{Storage}

Storage is an important consideration for wine that is being kept for long-term ageing and, fresh wine should be aged till it is drinkable and marketable, thus the evolution of the product in the bottle before its consumption is very important. The composition of wine is subjected to continuous changes during storage and these changes are a result of a function of parameters such as temperature, illumination, position of bottles, oxygen content and storage time. These changes are varied and intricate and can affect its aroma and colour, as well as its phenolic composition. The wine bottles can be easily stored for more than six months at temperature between $10^{\circ} \mathrm{C}$ to $25^{\circ} \mathrm{C}$ but the bottles should be air tight to stop the effect of humidity. These bottles can be kept at any dry place for longer storage.

\section{Sensory evaluation}

The sensory analysis of different treatments was conducted and presented to a panel of judges for organoleptic evaluation based on 9 - point Hedonic scale. The judges were same for each evaluation. They were asked to rinse their mouth before or in between testing the given sample. Each sample was evaluated on composite scores using 4 descriptors/quality attributes viz. colour and appearance, Taste, Aroma and overall impression/ acceptability (Amerine et al., 1980). Pineapple wine at initial and after 3 months of maturation was evaluated.

\section{Determination of Physio - chemical parameters}

The pineapple wine was analysed for the following quality parameters during fermentation and storage. In order to judge the suitability of pineapple fruit in preparation of wine, it is necessary to have a closer look on its physio-chemical composition. It was analysed for T.S.S ( ${ }^{\circ}$ Brix), Titratable acidity $(\%), \mathrm{pH}$, Alcohol content (\%) and Specific gravity.

\section{Determination of physio - chemical parameters}

The pineapple wine was analysed for the following quality parameters during fermentation and storage. In order to judge the suitability of pineapple fruit in preparation of wine, it is necessary to have a closer look on its physio-chemical composition. The periodically fermented samples were withdrawn by decanting them from the bottles 
and used for proximate analysis of T.S.S ( Brix), Titratable acidity (\%), pH, Alcohol content (\%) and Specific gravity whereas pineapple wine during storage was analysed for the following parameters.

Total soluble solids (TSS) of pineapple wine were measured using hand-held refractometer and the results were expressed as degree brix $\left({ }^{\circ} \mathrm{B}\right)$ at $20^{\circ} \mathrm{C}$ (AOAC, 2000). It was calibrated with distilled water. Titratable acidity was determined by titration of known weight of sample with $0.1 \mathrm{~N} \mathrm{NaOH}$ solution using a few drop of phenolphthalein as indicator (AOAC, 2000). Known volume of sample was made up to $100 \mathrm{ml}$ and filtered. $10 \mathrm{ml}$ of aliquot was titrated against $0.1 \mathrm{~N} \mathrm{NaOH}$ solution using phenolphthalein indicators. Acidity of sample was expressed as percent citric acid.

The must $\mathrm{pH}$ was determined using AOAC, (2004) procedure. The $\mathrm{pH}$ meter electrode was thoroughly rinsed with distilled water and reading adjusted to zero mark. The meter was then standardized in buffer 4 and 7 solution at $25^{\circ} \mathrm{C}$. Each $25 \mathrm{ml}$ of the must was pipette into a beaker and the $\mathrm{pH}$ electrode (probe) was dipped into the must and the reading allowed stabilizing before reading off.

Alcohol content was determined only by getting the specific gravity of the wines each day with their corresponding temperature. Using the alcohol determination chart/specific gravity, individual alcohol content for the wines was determined following the Institute of Brewing (IOB 1977) and Association of official Analytical Chemists (AOAC 2004). The amount of ethanol present in the samples was determined from the standard curve prepared similarly. Concentration of alcohol is expressed by percentage $(\mathrm{w} / \mathrm{v})$ in pineapple wine. Alcohol content in brandy was determined by alcoholmeter (Amerine et al., 1980).
Specific Gravity was determined according to Gregory (2005). A specific gravity bottle was filled with the sample, stopped and weighed. The same procedure was repeated for distilled water. It can also be determined using a density bottle (AOAC, 2004). The bottle was properly washed and kept in the oven to dry. The bottle and stopper were cooled in the desiccator and weighed accurately. The must and distilled water were cooled to $15.5^{\mathrm{O}} \mathrm{C}$, the bottle was filled with distilled water and stopper inserted and weighted. The bottle was then thoroughly cleaned and the process repeated with the fermenting must.

Must temperature be determined daily throughout the fermentation period using a thermometer with centigrade.

\section{Results and Discussion}

The result of the experiment entitled Effect of different levels of wine yeast and sugar in wine production from pineapple (Ananas comosus) was undertaken in the Post- Harvest Laboratory, Department of Horticulture, Sam Higginbottom University of Agriculture, Technology and Sciences, Prayagraj during the year 2019-2020. The results of the investigation regarding production of wine from pineapple influence by different levels of wine yeast and sugar have been presented in tables 1-3, wherever required.

\section{Total Soluble Solids (TSS)}

Total soluble solids of wine, at the end of fermentation period, is an important quality parameter and an indicative of the stability and completeness of fermentation. Changes in TSS during fermentation of pineapple juice inoculated with yeast Saccharomyces cerevisiae are presented in Table 1 . The rate of decrease in total soluble solids ( ${ }^{\circ}$ Brix) during fermentation differed significantly with the yeast strain as the fermentation time 
progressed and different yeast strain used. Decrease in TSS was also governed by the level of the inoculum rate ( 5 and $10 \% \mathrm{v} / \mathrm{v})$. In terms of Total Soluble Solids, the lowest score was observed in treatment $\mathrm{T}_{2}$ followed by treatment $\mathrm{T}_{4}$ whereas the maximum score was observed in treatment $\mathrm{T}_{9}$ at Initial, 30, 60, and 90 days storage.

The initial higher decrease in TSS during fermentation is attributed to the higher fermentability of musts because of more availability of sugar and less alcohol in the medium. Difference in TSS of wine fermented with different yeast strains at different inoculum levels, was due to variable ability of yeast strain to convert sugar to alcohol. In general, reduction in TSS was a function of time and was evidently due to the fermentation of sugar by the yeast. This is typical fermentation behaviour of any alcoholic fermentation of fruit juice into wine. The decrease in TSS content of wine indicates the utilization of the sugar present in the must during fermentation.

\section{Titratable acidity (TA)}

Acidity is an important factor, since it contributes both directly and indirectly to the quality of wines (Clarke and Bakker, 2004). TA of wines increased as fermentation progressed due to the presence of organic acids formed as a by-product. The changes in TA during fermentation are depicted in Table 1. After $24 \mathrm{~h}$ of fermentation, TA increased significantly, irrespective of the yeast strains used. This rise in acidity corresponds to the fall in reducing sugars content and increase in alcohol concentration.

The increase in acidity may be due to the increased alcohol production from the high initial sugar concentration (Attri, 2009). In terms of Acidity, the lowest score was observed in treatment $\mathrm{T}_{2}$ followed by treatment $\mathrm{T}_{4}$ whereas the maximum score was observed in treatment $\mathrm{T}_{9}$.

\section{pH}

The $\mathrm{pH}$ decreased gradually as the fermentation time increases. Variation observed was due to the effect of different yeast strain and fermentation period. Studies have shown that during fermentation of fruits, low $\mathrm{pH}$ is inhibitory to the growth of spoilage organisms but create conducive environment for the growth of desirable organisms. Also, low $\mathrm{pH}$ and high acidity are known to give fermentation yeast comparative advantage in natural environments. In terms of $\mathrm{pH}$, the lowest score was observed in treatment $T_{2}$ followed by treatment $\mathrm{T}_{4}$ whereas the maximum score was observed in treatment $\mathrm{T}_{9}$.

\section{Alcohol content}

Ethanol is the most important alcohol in wine and an index of quality of wine. Its concentration is crucial to the stability, ageing and sensory properties of the wine by acting as preservative, dissolving volatile compounds and affecting production of aromatic compounds. It is apparent from the results shown in Table 1 that with increase in fermentation time, concentration of alcohol increased. In terms of Alcohol content, the highest score was observed in treatment $T_{2}$ followed by treatment $\mathrm{T}_{4}$ whereas the minimum score was observed in treatment $T_{9}$.

\section{Specific gravity}

The specific gravity of the pineapple wine produced in this study reduces as the fermentation days of the wine increases. The decrease in Specific gravity of pineapple wine with different levels of wine yeast and sugar during storage may possibly be due to the type of yeast used in the wine production. 


\section{Int.J.Curr.Microbiol.App.Sci (2020) 9(12): 681-693}

Table.1 Physio- chemical parameters of effect of different levels of wine yeast and sugar in wine production from pineapple

\begin{tabular}{|c|c|c|c|c|c|c|c|c|c|c|c|c|c|c|c|c|c|c|c|c|}
\hline \multirow{2}{*}{$\begin{array}{l}\text { Treatment } \\
\text { Symbol }\end{array}$} & \multirow[b]{2}{*}{ Treatment Details } & \multicolumn{4}{|c|}{ Total Soluble Solids $\left({ }^{\circ}\right.$ Brix) } & \multicolumn{4}{|c|}{ Acidity (\%) } & \multicolumn{4}{|c|}{ pH (\%) } & \multicolumn{3}{|c|}{ Alcohol content } & \multicolumn{4}{|c|}{ Specific Gravity } \\
\hline & & Initial & $\begin{array}{c}30 \\
\text { DAS }\end{array}$ & $\begin{array}{c}60 \\
\text { DAS }\end{array}$ & $\begin{array}{c}90 \\
\text { DAS }\end{array}$ & $\begin{array}{c}\text { Initi } \\
\text { al }\end{array}$ & $\begin{array}{c}30 \\
\text { DAS }\end{array}$ & 60 DAS & $\begin{array}{c}90 \\
\text { DAS }\end{array}$ & $\begin{array}{c}\text { Initi } \\
\text { al }\end{array}$ & $\begin{array}{c}30 \\
\text { DAS }\end{array}$ & $\begin{array}{c}60 \\
\text { DAS }\end{array}$ & $\begin{array}{c}90 \\
\text { DAS }\end{array}$ & $\begin{array}{c}30 \\
\text { DAS }\end{array}$ & $\begin{array}{c}60 \\
\text { DAS }\end{array}$ & $\begin{array}{c}90 \\
\text { DAS }\end{array}$ & Initial & $\begin{array}{c}30 \\
\text { DAS }\end{array}$ & $\begin{array}{c}60 \\
\text { DAS }\end{array}$ & $\begin{array}{c}90 \\
\text { DAS }\end{array}$ \\
\hline $\mathbf{T}_{1}$ & $\begin{array}{c}\text { Pineapple juice }(700 \mathrm{ml})+ \\
\text { Sugar }(150 \mathrm{~g})+\text { Wine yeast } \\
(0.25 \mathrm{~g})\end{array}$ & 14.90 & 14.7 & 13.46 & 8.50 & 0.32 & 0.59 & 0.68 & 0.78 & 5.86 & 4.87 & 4.43 & 4.17 & 2.10 & 4.00 & 4.90 & 1.48 & 1.37 & 1.25 & 1.08 \\
\hline $\mathbf{T}_{2}$ & $\begin{array}{c}\text { Pineapple juice }(700 \mathrm{ml})+ \\
\text { Sugar }(200 \mathrm{~g})+\text { Wine yeast } \\
(1.5 \mathrm{~g})\end{array}$ & 15.26 & 13.06 & 11.33 & 6.50 & 0.32 & 0.41 & 0.49 & 0.61 & 5.93 & 4.10 & 3.91 & 3.67 & 4.10 & 6.30 & 7.93 & 1.52 & 1.22 & 1.07 & 0.94 \\
\hline $\mathbf{T}_{3}$ & $\begin{array}{c}\text { Pineapple juice }(700 \mathrm{ml})+ \\
\text { Sugar }(250 \mathrm{~g})+\text { Wine yeast } \\
(0.75 \mathrm{~g})\end{array}$ & 17.93 & 14.20 & 13.80 & 7.93 & 0.35 & 0.49 & 0.54 & 0.72 & 5.63 & 4.67 & 4.23 & 3.96 & 3.31 & 4.60 & 5.77 & 1.61 & 1.42 & 1.24 & 1.04 \\
\hline $\mathbf{T}_{4}$ & $\begin{array}{c}\text { Pineapple juice }(700 \mathrm{ml})+ \\
\text { Sugar }(150 \mathrm{~g})+\text { Wine yeast } \\
(0.75 \mathrm{~g})\end{array}$ & 15.93 & 13.70 & 11.93 & 6.97 & 0.37 & 0.43 & 0.57 & 0.68 & 5.86 & 4.36 & 3.96 & 3.80 & 3.62 & 5.36 & 6.17 & 1.32 & 1.39 & 1.14 & 0.98 \\
\hline $\mathbf{T}_{5}$ & $\begin{array}{c}\text { Pineapple juice }(700 \mathrm{ml})+ \\
\text { Sugar }(200 \mathrm{~g})+\text { Wine yeast } \\
(0.25 \mathrm{~g})\end{array}$ & 17.30 & 14.36 & 14.17 & 7.40 & 0.28 & 0.55 & 0.60 & 0.77 & 5.37 & 4.76 & 4.30 & 4.06 & 2.67 & 4.03 & 5.33 & 1.44 & 1.39 & 1.23 & 1.06 \\
\hline$T_{6}$ & $\begin{array}{c}\text { Pineapple juice }(700 \mathrm{ml})+ \\
\text { Sugar }(250 \mathrm{~g})+\text { Wine yeast } \\
(1.5 \mathrm{~g})\end{array}$ & 18.30 & 14.03 & 13.13 & 7.37 & 0.35 & 0.47 & 0.52 & 0.70 & 5.70 & 4.47 & 4.13 & 3.86 & 3.36 & 4.73 & 5.80 & 1.64 & 1.43 & 1.26 & 1.08 \\
\hline $\mathbf{T}_{7}$ & $\begin{array}{c}\text { Pineapple juice }(700 \mathrm{ml})+ \\
\text { Sugar }(150 \mathrm{~g})+\text { Wine yeast } \\
(1.5 \mathrm{~g})\end{array}$ & 16.80 & 15.33 & 14.13 & 9.23 & 0.27 & 0.60 & 0.71 & 0.82 & 5.80 & 4.97 & 4.60 & 4.27 & 2.70 & 3.73 & 4.33 & 1.43 & 1.37 & 1.22 & 1.06 \\
\hline $\mathbf{T}_{8}$ & $\begin{array}{c}\text { Pineapple juice }(700 \mathrm{ml})+ \\
\text { Sugar }(200 \mathrm{~g})+\text { Wine yeast } \\
(0.75 \mathrm{~g})\end{array}$ & 18.77 & 16.20 & 14.67 & 10.63 & 0.34 & 0.64 & 0.76 & 0.88 & 5.70 & 5.16 & 4.90 & 4.43 & 3.27 & 4.26 & 4.33 & 1.52 & 1.49 & 1.36 & 1.18 \\
\hline $\mathbf{T}_{9}$ & $\begin{array}{c}\text { Pineapple juice }(700 \mathrm{ml})+ \\
\text { Sugar }(250 \mathrm{~g})+\text { Wine yeast } \\
(0.25 \mathrm{~g})\end{array}$ & 19.10 & 17.06 & 15.33 & 11.80 & 0.26 & 0.65 & 0.80 & 0.92 & 5.36 & 5.13 & 5.13 & 4.83 & 2.47 & 3.67 & 3.87 & 1.58 & 1.42 & 1.31 & 1.25 \\
\hline & F-Test & $\mathrm{S}$ & $\mathrm{S}$ & $\mathrm{S}$ & $\mathrm{S}$ & S & $\mathrm{S}$ & S & $\mathrm{S}$ & $\mathrm{S}$ & $\mathrm{S}$ & $\mathrm{S}$ & $\mathrm{S}$ & S & $\mathrm{S}$ & $\mathrm{S}$ & S & $\mathrm{S}$ & $\mathrm{S}$ & S \\
\hline & C.V. & 2.024 & 1.747 & 1.427 & 4.678 & $\begin{array}{l}8.04 \\
0\end{array}$ & 5.011 & 3.749 & 3.073 & $\begin{array}{l}3.15 \\
3\end{array}$ & 1.823 & 2.704 & 3.679 & 5.894 & 5.897 & 1.677 & 1.246 & 0.952 & 1.304 & 0.590 \\
\hline & $\operatorname{SE}(d)$ & 0.283 & 0.21 & 0.158 & 0.324 & $\begin{array}{l}0.02 \\
1\end{array}$ & 0.022 & 0.019 & 0.019 & $\begin{array}{l}0.14 \\
7\end{array}$ & 0.07 & 0.097 & 0.124 & 0.147 & 0.218 & 0.074 & 0.015 & 0.011 & 0.013 & 0.005 \\
\hline & C.D. at 5\% & 0.6 & 0.445 & 0.334 & 0.686 & $\begin{array}{l}0.04 \\
4\end{array}$ & 0.047 & 0.041 & 0.041 & 0.31 & 0.149 & 0.206 & 0.262 & 0.312 & 0.461 & 0.156 & 0.032 & 0.023 & 0.028 & 0.011 \\
\hline
\end{tabular}


Table.2 Organoleptic score of effect of different levels of wine yeast and sugar in wine production from pineapple

\begin{tabular}{|c|c|c|c|c|c|c|c|c|c|c|c|c|c|}
\hline \multirow{2}{*}{$\begin{array}{l}\text { Treatmen } \\
\text { t Symbol }\end{array}$} & \multirow{2}{*}{ Treatment Details } & \multicolumn{3}{|c|}{ Colour and Appearance } & \multicolumn{3}{|c|}{ Taste } & \multicolumn{3}{|c|}{ Aroma } & \multicolumn{3}{|c|}{ Overall acceptability } \\
\hline & & 30 DAS & 60 DAS & 90 DAS & 30 DAS & 60 DAS & 90 DAS & 30 DAS & 60 DAS & 90 DAS & 30 DAS & 60 DAS & 90 DAS \\
\hline $\mathbf{T}_{1}$ & $\begin{array}{c}\text { Pineapple juice }(700 \mathrm{ml})+ \\
\text { Sugar }(150 \mathrm{~g})+\text { Wine yeast } \\
(0.25 \mathrm{~g})\end{array}$ & 3.66 & 4.00 & 4.33 & 3.67 & 4.00 & 4.33 & 3.67 & 4.00 & 4.33 & 3.33 & 3.67 & 4.00 \\
\hline $\mathbf{T}_{2}$ & $\begin{array}{c}\text { Pineapple juice }(700 \mathrm{ml})+ \\
\text { Sugar }(200 \mathrm{~g})+\text { Wine yeast } \\
(1.5 \mathrm{~g})\end{array}$ & 7.33 & 7.33 & 7.67 & 7.33 & 7.66 & 8.00 & 7.00 & 7.33 & 7.67 & 6.66 & 7.00 & 7.67 \\
\hline $\mathbf{T}_{\mathbf{3}}$ & $\begin{array}{c}\text { Pineapple juice }(700 \mathrm{ml})+ \\
\text { Sugar }(250 \mathrm{~g})+\text { Wine yeast } \\
(0.75 \mathrm{~g})\end{array}$ & 5.00 & 5.00 & 5.33 & 3.67 & 4.67 & 4.66 & 3.33 & 3.67 & 4.00 & 3.66 & 4.00 & 4.33 \\
\hline $\mathbf{T}_{4}$ & $\begin{array}{c}\text { Pineapple juice }(700 \mathrm{ml})+ \\
\text { Sugar }(150 \mathrm{~g})+\text { Wine yeast } \\
(0.75 \mathrm{~g})\end{array}$ & 5.67 & 6.00 & 6.33 & 6.33 & 6.67 & 7.00 & 5.67 & 6.00 & 6.67 & 5.67 & 6.00 & 6.67 \\
\hline $\mathbf{T}_{5}$ & $\begin{array}{c}\text { Pineapple juice }(700 \mathrm{ml})+ \\
\text { Sugar }(200 \mathrm{~g})+\text { Wine yeast } \\
(0.25 \mathrm{~g})\end{array}$ & 4.00 & 4.67 & 4.66 & 4.33 & 5.00 & 5.33 & 4.33 & 4.67 & 5.00 & 4.33 & 4.67 & 5.00 \\
\hline $\mathbf{T}_{6}$ & $\begin{array}{c}\text { Pineapple juice }(700 \mathrm{ml})+ \\
\text { Sugar }(250 \mathrm{~g})+\text { Wine yeast } \\
(1.5 \mathrm{~g})\end{array}$ & 3.00 & 3.67 & 5.00 & 5.33 & 5.33 & 6.00 & 3.00 & 3.33 & 3.67 & 3.00 & 4.67 & 5.00 \\
\hline $\mathbf{T}_{7}$ & $\begin{array}{c}\text { Pineapple juice }(700 \mathrm{ml})+ \\
\text { Sugar }(150 \mathrm{~g})+\text { Wine yeast } \\
(1.5 \mathrm{~g})\end{array}$ & 4.00 & 4.33 & 4.66 & 5.00 & 5.66 & 5.67 & 4.00 & 4.33 & 4.67 & 4.00 & 4.33 & 4.67 \\
\hline $\mathbf{T}_{8}$ & $\begin{array}{c}\text { Pineapple juice }(700 \mathrm{ml})+ \\
\text { Sugar }(200 \mathrm{~g})+\text { Wine yeast } \\
(0.75 \mathrm{~g})\end{array}$ & 4.66 & 5.00 & 5.00 & 5.00 & 5.33 & 5.33 & 4.67 & 5.00 & 5.00 & 4.67 & 5.00 & 5.33 \\
\hline $\mathbf{T}_{9}$ & $\begin{array}{c}\text { Pineapple juice }(700 \mathrm{ml})+ \\
\text { Sugar }(250 \mathrm{~g})+\text { Wine yeast } \\
(0.25 \mathrm{~g})\end{array}$ & 1.66 & 2.33 & 3.00 & 2.00 & 2.66 & 3.00 & 1.67 & 2.33 & 3.00 & 1.67 & 2.33 & 3.00 \\
\hline & F-Test & $\mathrm{S}$ & $\mathrm{S}$ & $\mathrm{S}$ & $\mathrm{S}$ & $\mathrm{S}$ & $\mathrm{S}$ & $\mathrm{S}$ & $\mathrm{S}$ & $\mathrm{S}$ & $\mathrm{S}$ & $\mathrm{S}$ & $\mathrm{S}$ \\
\hline & C.V. & 5.449 & 4.365 & 1.245 & 5.766 & 4.327 & 0.998 & 5.868 & 4.64 & 0.815 & 5.894 & 4.459 & 0.880 \\
\hline & SE(d) & 0.72 & 0.588 & 0.521 & 0.703 & 0.471 & 0.416 & 0.703 & 0.385 & 0.385 & 0.72 & 0.416 & 0.351 \\
\hline
\end{tabular}


Table.3 Economics of different treatments and benefit cost ratio

\begin{tabular}{|c|c|c|c|c|c|c|c|}
\hline Treatment No. & Treatment & $\begin{array}{l}\text { Total cost } \\
\quad(\mathrm{Rs})\end{array}$ & $\begin{array}{c}\text { Pineapple } \\
\text { wine output } \\
\text { (liter) }\end{array}$ & $\begin{array}{c}\text { Selling } \\
\text { rate } \\
\text { (Rs/per } \\
\text { liter) }\end{array}$ & $\begin{array}{c}\text { Gross } \\
\text { return } \\
(\mathrm{Rs})\end{array}$ & $\begin{array}{c}\text { Net } \\
\text { return } \\
(\mathbf{R s})\end{array}$ & $\begin{array}{c}\text { Benefit } \\
\text { cost } \\
\text { ratio }\end{array}$ \\
\hline $\mathbf{T}_{1}$ & $\begin{array}{l}\text { Pineapple juice }(700 \mathrm{ml})+\text { Sugar } \\
(150 \mathrm{~g})+\text { Wine yeast }(0.25 \mathrm{~g})\end{array}$ & 831.1 & 1.00 & 1300 & 1300 & 468.9 & 1.56 \\
\hline $\mathbf{T}_{2}$ & $\begin{array}{l}\text { Fruit juice }(700 \mathrm{ml})+\text { Sugar }(200 \mathrm{~g})+ \\
\text { Wine yeast }(1.5 \mathrm{~g})\end{array}$ & 833.45 & 1.00 & 1400 & 1400 & 566.55 & 1.67 \\
\hline $\mathbf{T}_{\mathbf{3}}$ & $\begin{array}{l}\text { Fruit juice }(700 \mathrm{ml})+\text { Sugar }(250 \mathrm{~g})+ \\
\text { Wine yeast }(0.75 \mathrm{~g})\end{array}$ & 835.25 & 1.00 & 1300 & 1300 & 464.75 & 1.55 \\
\hline $\mathbf{T}_{4}$ & $\begin{array}{l}\text { Fruit juice }(700 \mathrm{ml})+\text { Sugar }(150 \mathrm{~g})+ \\
\text { Wine yeast }(0.75 \mathrm{~g})\end{array}$ & 831.25 & 1.0 & 1500 & 1500 & 668.75 & 1.80 \\
\hline $\mathbf{T}_{5}$ & $\begin{array}{l}\text { Fruit juice }(700 \mathrm{ml})+\text { Sugar }(200 \mathrm{~g})+ \\
\text { Wine yeast }(0.25 \mathrm{~g})\end{array}$ & 833.1 & 1.00 & 1300 & 1300 & 466.9 & 1.56 \\
\hline $\mathbf{T}_{6}$ & $\begin{array}{l}\text { Fruit juice }(700 \mathrm{ml})+\text { Sugar }(250 \mathrm{~g})+ \\
\text { Wine yeast }(1.5 \mathrm{~g})\end{array}$ & 835.45 & 1.00 & 1300 & 1300 & 464.55 & 1.55 \\
\hline $\mathbf{T}_{7}$ & $\begin{array}{l}\text { Fruit juice }(700 \mathrm{ml})+\text { Sugar }(150 \mathrm{~g})+ \\
\text { Wine yeast }(1.5 \mathrm{~g})\end{array}$ & 831.45 & 1.00 & 1300 & 1300 & 468.55 & 1.56 \\
\hline $\mathbf{T}_{8}$ & $\begin{array}{l}\text { Fruit juice }(700 \mathrm{ml})+\text { Sugar }(200 \mathrm{~g})+ \\
\text { Wine yeast }(0.75 \mathrm{~g})\end{array}$ & 833.25 & 1.00 & 1300 & 1300 & 466.75 & 1.56 \\
\hline $\mathbf{T}_{9}$ & $\begin{array}{l}\text { Fruit juice }(700 \mathrm{ml})+\text { Sugar }(250 \mathrm{~g})+ \\
\text { Wine yeast }(0.25 \mathrm{~g})\end{array}$ & 835.1 & 1.00 & 1000 & 1000 & 164.9 & 1.19 \\
\hline
\end{tabular}


Saccharomyces cerevisiae has been reported to reduce specific quality of fruit wines during fermentation. In terms of Specific gravity, the lowest score was observed in treatment $T_{2}$ followed by treatment $\mathrm{T}_{4}$ whereas the maximum score was observed in treatment $\mathrm{T}_{9}$.

\section{Colour and appearance}

The colour and appearance of pineapple wine was showed increasing trend in all pineapple wine during storage. Change in colour of White wine from yellow to yellow-brown during the storage period. Various reactions including oxidation, condensation and polymerization may result in colour change, the decrease in lightness observed during storage at 3 months could be attributed to the various reactions. In terms of colour and appearance, the maximum score was observed in treatment $T_{2}$ followed by treatment $T_{4}$ whereas the minimum score was observed in treatment $\mathrm{T}_{9}$ at 30,60 , and 90 days storage.

\section{Taste}

The Taste of pineapple wine was showed increasing trend in all pineapple wine during storage. As the wine ages properly, the harsh taste and yeasty odour diminish and a smooth mellow flavour and clean odour are produced (Amerine et al., 1980). Since pineapples contains high amount of citric acid, malic acid and ascorbic acid, due to the presence of these acids, the contamination of wines will be reduced and it also increases the taste of wine. In terms of Taste, the maximum score was observed in treatment $\mathrm{T}_{2}$ followed by treatment $\mathrm{T}_{4}$ whereas the minimum score was observed in treatment $\mathrm{T}_{9}$.

\section{Aroma}

The Aroma of pineapple wine was showed increasing trend in all pineapple wine during storage. The type and aroma produced during wine production is reported to depend on yeast, environmental factors and physiochemical characteristics of the "musts". In terms of Aroma, the maximum score was observed in treatment $\mathrm{T}_{2}$ followed by treatment $\mathrm{T}_{4}$ whereas the minimum score was observed in treatment $\mathrm{T}_{9}$.

\section{Overall acceptability}

The Overall acceptability of pineapple wine was showed increasing trend in all pineapple wine during storage. High overall quality score observed in pineapple wine may be due to original good sensory properties of juice, appreciable fermentation of juice by yeast which is indicated by high alcohol content. Maturation altered various components of wine, which are desirable for the sensory quality. The reduction in phenolic compounds in white wines produced a decrease in body and astringency (Gallego et al., 2013). In terms of Overall acceptability, the maximum score of Overall acceptability was observed in treatment $T_{2}$ followed by treatment $T_{4}$ whereas the minimum score was observed in treatment $\mathrm{T}_{9}$.

\section{Cost benefit ratio}

The Cost Benefit Ratio showed that there were significant differences among all the treatments in Cost Net Return, Gross Return and Cost Benefit Ratio of different treatments. In terms of Cost Benefit Ratio, the maximum cost benefit ratio was recorded in $\mathrm{T}_{4}$ which is followed by $\mathrm{T}_{2}$ whereas lowest cost benefit ratio was recorded in $T_{9}$.

Based on findings of the present experiment it is concluded that treatment $\mathrm{T}_{2}$ (Pineapple juice 700ml + Sugar 200g + Wine Yeast 1.5g) was found superior in respect of the parameters like Total Soluble Solids, Acidity, $\mathrm{pH}$, Alcohol content, Specific gravity. With respectively Colour and Appearance, Taste, 
Aroma and Overall acceptability also $\mathrm{T}_{2}$ was found best. In terms of cost benefit ratio, the highest net return, Cost Benefit Ratio was found in $\mathrm{T}_{4}$ (Pineapple juice $700 \mathrm{ml}+$ Sugar $150 \mathrm{~g}+$ Wine Yeast $0.75 \mathrm{~g}$ )

\section{References}

A.O.A.C. (2000) Official methods of analysis. $17^{\text {th }}$ Edn. Association of Official Analytical Chemists, Gaithersburg, MD

Akubor, P. I., Obio, S. O., Nwadomere, K. A. and Obiomah, E. (2003) Production and quality evaluation of banana wine. Plants Foods for Human Nutrition, 58: 1-6.

Alves, J. A., Lima, L. C. O., Nunes, C. A., Dias, D. R. and Schwan, R.F. (2011) Chemical, physical-chemical and sensory characteristics of lychee (Litchi chinensis Sinn) wines. Journal of Food Science, 76 (5): 330-336.

Amerine, M. A. and Ough, C. S. (1979) Wine and Must Analysis. 2 ${ }^{\text {nd }}$ Edn. John Wiley and Sons, New York.

Amerine, M. A., Berg, H. W., Kunkee, R. E., Ough, C. S., Singleton, V. L. and Webb, A. D. (1980) Technology of Wine Making. $4^{\text {th }}$ Edn. AVI Publishing Co., Inc. Westport, CT.

Attri, B. L. (2009) Effect of initial concentration on the physicochemical characteristics and sensory qualities of cashew apple wine. Indian Journal of Natural Products and Resources, 8: 374- 379.

Bartholomew, D. P., Paul, R. E. and Rohrbach. K. G. (2003) The Pineapple: Botany, Production and Uses. D. P. Bartholomew, R. E. Paul and K. G. Rohrbach (Eds.). CABI Publishing, Wallingford, UK, pp. 130.

Chanprasartsuk, O., Pheanudomkitlert, K. and Toonwai, D. (2012) Pineapple wine fermentation with yeasts isolated from fruit as single and mixed starter cultures. Asian Journal Food AgroIndustry, 5 (2): 104-111.

Chowdhury, P. and Ray, R. C. (2007) Fermentation of jamun (Syzgium cumini L) fruits to form red wine. ASEAN Food Journal, 14 (1): 15- 23.

Clarke, R. J. and Bakker, J. (2004) Volatile components. In: Wine flavour chemistry. Blackwell Publishing Limited, Oxford, UK, pp. 120- 188.

Clemente, E. and Scapim, C. A. (2005) Cold storage of pineapple 'smooth cayenne' under different types of packaging. Journal of Food Technology, 3: 242246.

Das, D., Mukherjee, S. and Ray, D. (2010) Resveratrol and red wine, healthy heart and longevity. Heart Failure Reviews, 15: 467-477.

Gallego, M. A. G, García- Carpintero, E. G., Sánchez-Palomo, E., Viñas, M. A. G. and Hermosín- Gutiérrez, I. (2013) Evolution of the phenolic content, chromatic characteristics and sensory properties during bottle storage of red single- cultivar wines from Castilla $\mathrm{La}$ Mancha region. Food Research International, 51: 554-563.

German, J. B. and Walzem, R. L. (2000) The health benefits of wine. Annual Review of Nutrition, 20: 561- 593.

Joshi, V. K., Sharma, S. and Devi, M. P. (2009) Influence of different yeast strains on fermentation behaviour, physico- chemical and sensory qualities of plum wine. Indian Journal of Natural Products and Resources, 8(4): 445-451.

Kirtadze, E. and Nutsubidze, N. (2009) Metabolic potential of alcoholic fermentation yeasts. Bulletin of Georgian Nature Academy of Sciences, 3(1): 112-116

Kumar, V., Goud, P. V., Babu, J. D. and 
Reddy, R. S. (2011) Preparation and evaluation of custard apple wine: Effect of dilution of pulp on physicochemical and sensory quality characteristics. International Journal of Food Fermentation Technology, 1(2): 247-253.

Lee, K., Zhao, J. and Ko, J. Y. (2005) Exploring the Korean wine market. Journal of Hospitality and Tourism Research, 29 (1): 20- 41.

Sharma, S. and Joshi, V. K. (2003) Effect of maturation on the physico chemical and sensory quality of strawberry wine. Journal of Scientific and Industrial Research, 62 (6): 601- 608. Wu, H. C., Wang, X. X., Ning, Z. X., Gao, J. H., Wei, Q. Y., Zhao, L. T. and Liang, G. Y. (2012) Study on the quality of brewed pineapple wine and its stability. Modern Food Science and Technology, 28 (2): 191-194.

\section{How to cite this article:}

Kithan Thungbeni, Topno E. Samir and Wilson Deena. 2020. Effect of Different Levels of Wine Yeast and Sugar in Wine Production from Pineapple (Ananas comosus). Int.J.Curr.Microbiol.App.Sci. 9(12): 681-693. doi: https://doi.org/10.20546/ijcmas.2020.912.082 